\title{
The Comparison of Stress Between Chinese High School Students and American High School Students
}

\author{
Weidi Hu, Wenjing Zhang \\ Village Academy, Liberty St Powell, USA
}

\begin{abstract}
To better understand the American high school life, this study make a comparison of the study situation and stress level between American and Chinese high school students. The method s of the study is evaluating the high school study and stress of 48 American students and 43 Chinese students through survey. The results show that Chinese high school students spend more time doing homework and less time sleeping and playing sports than American high school students $(p<0.05)$. In contrast, American high school students are more active in participate in extra-curricular activities and sports. Though Chinese and American high school students have different plans in daily time distribution of study, extra-curricular activities, etc., both groups share similar academic stress.
\end{abstract}

Keywords: stress, China and United States (U.S.), high school students

\section{Introduction}

In recent years, with the rapid economic growth and the boost of globalization, more and more students in China go abroad to study in foreign countries. United States (U.S.), as one of the most developed countries in the world, has become the prime choice for the Chinese students who want to go abroad. According to Institute of International Education (IIE), 304,040 students from China were studying in the U.S. in the 2014-2015 academic years (up 10.8\% from the previous year) (IIE, 2015). Simultaneously, China Education Online (2016) published an article showed 34,578 Chinese students were studying in U.S. primary and middle schools in 2015, accounting for $52 \%$ of all international students and this number keeps surging.

In most Chinese parents' eyes, American education is a kind of humanized education, so that it fully develops students' potential and meets students' need for personality development. It does not put much pressure on them, so they could study happily and have time to foster their interests. Instead of only teaching them test-oriented skills and putting tremendous stress on them. There is a stereotype that people think American students do not study hard. In fact, they are able to study and play at the same time. Once parents send their children to the U.S., all their children could achieve good grades without studying extremely hard. However, there has been no solid evidence, researches, or report on how are the Chinese and American high school student's academic study, extra-curricular activities, study stress, the sources, and the ways of dealing their stress similar or different. Therefore, in order to help people better understand the situation of Chinese students and American students, and to provide a clear view for the parents and children who want to study abroad, this research compares those two groups of students.

Weidi Hu, high school student, Village Academy.

Wenjing Zhang, M.A., teacher, Department of English Language Learning, Village Academy. 


\section{Subject and Methods}

\section{Subject}

Students from the Village Academy are chosen as the representatives of the American high school students. Chinese students are selected from Shanghai Shixi High School, Shanghai Yucai High School, and Shanghai Xiangming High School. Surveys were sent through Wechat or e-mailed to the tested subjects and all the surveys were completed voluntarily.

\section{Method}

The research was done in the form of survey, which was self-designed after looking up related literature as references. The survey includes students' basic information, their study condition, extra-curricular activities, stress level, sources of stress, and the ways they deal with it.

\section{Statistical Analysis}

The statistical analysis system (SAS) 9.1 software was adopted for the data analysis, quantitative data are described in the way of $X \pm s$, the comparison of the two groups is examined by $t$, and count data is expressed in percentile ( $p<0.05$ is statistically significant).

\section{Result}

\section{General Comparison}

Forty-eight surveys from American students and 43 surveys from Chinese students have been collected. The genders between those two groups have no significant difference $\left(X^{2}=0.3571, p=0.5501\right)$. Student's gender, grade, and health situation can be seen in Table 1.

Table 1

General Comparison

\begin{tabular}{llcc}
\hline & & American $(N=48)$ & Chinese $(N=43)$ \\
\hline \multirow{2}{*}{ Gender } & Male & $15(31.25 \%)$ & $9(20.93 \%)$ \\
& Female & $33(68.75 \%)$ & $34(79.07 \%)$ \\
\hline \multirow{5}{*}{ Grade } & 9 & $23(47.92 \%)$ & $0(0 \%)$ \\
& 10 & $12(25.00 \%)$ & $26(60.47 \%)$ \\
& 11 & $5(10.42 \%)$ & $16(37.21 \%)$ \\
& 12 & $8(16.67 \%)$ & $1(2.32 \%)$ \\
\hline \multirow{3}{*}{ Health condition } & Fery good & $21(43.75 \%)$ & $16(37.21 \%)$ \\
& Good & $23(47.92 \%)$ & $5(11.63 \%)$ \\
& Poor & $0(0 \%)$ & $1(2.32 \%)$ \\
& Very poor & $2(4.17 \%)$ & $0(0 \%)$ \\
\hline
\end{tabular}

Note. In China, Grade 9 is included in middle school, thus there is no ninth graders in the Chinese representatives.

\section{Time Distribution}

Compare to American students, Chinese high school students spend more time on their homework every day, but have less time to sleep and do sports (see Table 2). 
Table 2

Time Distribution

\begin{tabular}{llll}
\hline & American $(N=48)$ & Chinese $(N=43)$ & $p$-value \\
\hline Time spending on homework each day (min.) & $161.25 \pm 69.63$ & $207.67 \pm 78.26$ & 0.0039 \\
Sport-playing time each week (min.) & $449.64 \pm 310.90$ & $175.24 \pm 148.82$ & 0.0002 \\
Sleep time each day (min.) & $421.25 \pm 92.86$ & $385.12 \pm 75.71$ & 0.0488 \\
\hline
\end{tabular}

Note. $p<0.05$.

\section{Extra-Curricular Activities}

There is $81.40 \%$ Chinese students participate in cram classes (after school classes). In comparison, the data in American student is only $18.37 \%$.

In addition, both groups of students have abundant extra-curricular activities. Although the percentage of American students who join clubs (85.42\%) is higher than the percentage of Chinese students who join clubs (72.09\%), there is no marked difference exist $(p=0.1185)$. For American students, the most popular activities are sports. For Chinese students, they prefer to choose art (see Table 3).

Table 3

The Comparison of the Numbers of American and Chinese students in Each Type of Clubs

\begin{tabular}{lcc}
\hline & American $(N=48)$ & Chinese $(N=43)$ \\
\hline Volunteer & $26(54.17 \%)$ & $4(9.30 \%)$ \\
Art & $15(31.25 \%)$ & $17(39.53 \%)$ \\
Sport team & $31(64.58 \%)$ & $1(2.33 \%)$ \\
Academics & $20(41.67 \%)$ & $6(13.95 \%)$ \\
Others & $3(6.25 \%)$ & $6(13.95 \%)$ \\
\hline
\end{tabular}

Note. $p<0.05$.

\section{Stress' Sources and Relieving Ways of American and Chinese Students}

In the survey, the study stress and the stress of going to a college used a score from 1 to 5 ( 1 = "No stress at al" and 5 = "Having too much stress"). Students from both countries feel stress with no significant difference (see Table 4).

Table 4

Comparison of Study Stress

\begin{tabular}{llll}
\hline & American $(N=48)$ & Chinese $(N=43)$ & $p$-value \\
\hline Study stress & $3.48 \pm 1.32$ & $3.12 \pm 0.82$ & 0.8018 \\
Stress of going to a college & $3.31 \pm 0.79$ & $2.82 \pm 0.62$ & 0.1911 \\
\hline
\end{tabular}

Table 5

Comparison of Stress's Sources

\begin{tabular}{lll}
\hline & American $(N=48)$ & Chinese $(N=43)$ \\
\hline Parents & $29(60.42 \%)$ & $29(67.44 \%)$ \\
Self-requirement & $37(77.08 \%)$ & $25(58.14 \%)$ \\
Peer competition & $13(27.08 \%)$ & $26(60.47 \%)$ \\
Academic scores & $34(70.83 \%)$ & $35(81.40 \%)$ \\
Go to an ideal college & $32(66.67 \%)$ & $21(48.84 \%)$ \\
Uncertainty of the future & $25(52.08 \%)$ & $34(79.07 \%)$ \\
\hline
\end{tabular}


Among several sources of stress, American students' stress mainly comes from self-requirement (77.08\%), while Chinese students' stress mainly comes from test scores (81.40\%) (see Table 5).

Among the ways people dealing with stress, the first three choices chosen by both two groups are the same, which are listening to music (70.83\% vs. $93.02 \%)$, entertainment $(56.25 \%$ vs. $72.09 \%)$, and sleeping (56.25\% vs. 69.77\%) (see Table 6).

Table 6

Ways of Relieving Stress of American and Chinese Students

\begin{tabular}{lll}
\hline & American $(N=48)$ & Chinese $(N=43)$ \\
\hline Listening to music & $34(70.83 \%)$ & $40(93.02 \%)$ \\
Reading books & $11(22.92 \%)$ & $19(44.19 \%)$ \\
Chatting with friends & $21(43.75 \%)$ & $25(58.14 \%)$ \\
Sleeping & $27(56.25 \%)$ & $30(69.77 \%)$ \\
food & $24(50 \%)$ & $29(67.44 \%)$ \\
Exercising & $26(54.17 \%)$ & $14(32.56 \%)$ \\
Entertainment & $27(56.25 \%)$ & $31(72.09 \%)$ \\
Playing video games & $21(43.75 \%)$ & $23(53.49 \%)$ \\
psychological consultation & $2(4.17 \%)$ & $1(2.33 \%)$ \\
\hline
\end{tabular}

\section{Discussion}

Different from American high school, Chinese high schools start from Grade 10-12. Thus, this research does not include Chinese ninth grader students.

This research shows compared to American high school students, Chinese high school students indeed study more time, but have less sleep and exercise. According to the research done by Wang and others, 94.4\% of Chinese high school students' sleep time less than eight hours every day (Wang et al., 2016). Furthermore, different from American high school students, most Chinese students' stress comes from parents' expectations and scores. These phenomenons are caused by two countries' different evaluation system. In China, people completely evaluate if he/she is a good student or not based on the student's grade. Only students who have excellent grades are able to go to good colleges, and then, they can find ideal jobs. In order to achieve good grades and to stand out from millions of peer competitors, high school students do numerous homework and attend extra-curricular classes. Meanwhile, China has been carrying out the one-child policy for decades, so most of the students are the only child of their family. Therefore, parents put huge expectation on them. It may also explain that there is $81.40 \%$ of Chinese high school students go to after-school classes, but there is only 18.37\% American high school students who do so.

In their spare time, both American and Chinese actively participate in all kinds of clubs and extra-curricular activities, however, American students spend more time in sports which in this research. The time they spend on sports were 2.5 times greater than the time Chinese high school students spend on sports. According to other research, there were approximately 45 million children and adolescent participated sports in the U.S. (Merkel, 2013). Conversely with the Chinese, Americans think highly of playing sports. Besides academic grades, students who are good at playing sports tend to be more popular in schools that they have more friends and have more voice. As a result, although nowadays Chinese secondary education has become more and more similar to international trend, extra-curricular activities are becoming more and more diversified and popularized, but there is a small gap existing between the numbers of students' participation in clubs 
(China [72.09\%] vs. U.S. [85.42\%]).

Being different from what Chinese parents have always expected, the research shows American students have as much academic stress as Chinese students do. While most Chinese students' stress comes from parents' expectations and scores, most American students' stress comes from self-requirement. Similarly, American students face big study stress as well. The college admission is a comprehensive assessment, meaning students not only need to do well in their standardized test and their performance in school courses, but also they need to show their strengths in leadership, extra-curricular activities, community service, sports, talents, etc.. Thus, a student who wants to be competitive in admission process, he/she needs to spend time on all these aspects that a typical Chinese high school student does not need to.

Because of the similarity in ages of two groups' students, their stress dealing ways are similar too. Most of them include listening to music, participating in entertainment, and sleeping. Few people need to seek the help from counseling.

Due to the lack of a great numbers of samples and most participants were female, students' study and stress cannot be analyzed based on different grades and academic performance. Furthermore, the international students who are studying in the U.S. were not included in this study. Therefore, to avoid making blind decision of sending children to study abroad and to conclude a more universal result of how the high school students' study life and stress in America and China are different, the study should be conducted a large number of participants all across the America and China, and from multiple different schools, and living conditions.

\section{Conclusion}

In conclusion, the research shows on the time distribution aspect, Chinese students spend more time on their homework and tutoring than American students, but have less time for sleeping and exercising. Nevertheless, research shows that the two countries' students both have huge study pressure that there is no distinct disparity. In addition, because of the differences between two countries' cultures and current situations, it could not be simply judged which kind of education is better based on students' study, life, and stress, etc.. This research is conducted only to provide a basic and authentic view for those families who want to send their children to study in the U.S. and to help each child find his/her own route. Also, it provides information for the staffs who work in the American or Chinese education system.

\section{References}

China Education Online. (2016). Report of development and trends of studying abroad of China in 2016. Retrieved October 1, 2016, from http://www.eol.cn

China Institute of International Education (IIE). (2015). Open doors: Report on International Educational Exchange. Retrieved October 1, 2016, from https://www.iie.org/Research-and-Insights/Open-Doors/Data/International-Students/Leading-Placesof-Origin/2014-15

Merkel, D. (2013). Youth sport: Positive and negative impact on young athletes. Open Access Journal of Sports Medicine, 4, 151-160.

Wang, G., Ren, F., Liu, Z., Xu, G., Jiang, F., Skora, E., \& Lewin, D. S. (2016). Sleep patterns and academic performance during preparation for college entrance exam in Chinese adolescents. Journal of School Health, 86(4). Retrieved February 23, 2017, from http://dx.doi.org/10.1111/josh.12379 